\title{
A Study on Applying Biomass Fraction for Greenhouse Gases Emission Estimation of a Sewage Sludge Incinerator in Korea: A Case Study
}

\author{
Seongmin Kang ${ }^{1}$, Seungjin Kim ${ }^{2}$, Jeongwoo Lee ${ }^{3}$, Youngjae Jeon ${ }^{1}$, Ki-Hyun Kim ${ }^{4}$ and \\ Eui-chan Jeon 1 ,* \\ 1 Department of Environment \& Energy, Sejong University, Seoul 05006, Korea; \\ smkang9804@gmail.com (S.K.); joiboy@naver.com (Y.J.) \\ 2 Cooperate Course for Climate Change, Sejong University, Seoul 05006, Korea; kimseungjin8611@gmail.com \\ 3 Department of Earth and Environmental Sciences, Sejong University, Seoul 05006, Korea; \\ leejwsky@gmail.com \\ 4 Department of Civil \& Environmental Engineering at Hanyang University, Seoul 04763, Korea; \\ kkim61@hanyang.ac.kr \\ * Correspondence: ecjeon@sejong.ac.kr; Tel.: +82-2-3408-4353
}

Academic Editor: Elena Cristina Rada

Received: 9 February 2017; Accepted: 1 April 2017; Published: 6 April 2017

\begin{abstract}
According to the IPCC (Intergovernmental Panel on Climate Change) guidelines, when calculating $\mathrm{CO}_{2}$ emissions, $\mathrm{CO}_{2}$ emissions from biomass should be excluded from the total amount of $\mathrm{CO}_{2}$ emissions and should be separately reported due to their "carbon neutrality". Sewage sludge is one of the representative biomass fuels. It is mixed with fossil fuels to achieve greenhouse gas reduction or is used by itself as a fuel to replace fossil fuels. According to the results of this study, biomass fractions of both the sewage sludge and the sewage sludge incineration exhaust gases did not amount to 100\%. At present, in many countries (South Korea, Japan, and Germany), when calculating greenhouse gas emissions from sewage sludge incinerators, all $\mathrm{CO}_{2}$ emissions from sewage sludge are judged to be biomass and only the greenhouse gas emissions that correspond to non- $\mathrm{CO}_{2}$ gases are calculated as greenhouse gas emissions. However, since, according our results, the content of sewage sludge is not $100 \%$ biomass, if $\mathrm{CO}_{2}$ emissions are excluded according to the existing greenhouse gas emission calculation method, the amount of emissions may be underestimated. Therefore, to accurately calculate greenhouse gas emissions from a sewage sludge incinerator, $\mathrm{CO}_{2}$ emissions should be calculated in consideration of the fossil carbon fractions of sewage sludge.
\end{abstract}

Keywords: sewage sludge; biomass fraction; sewage sludge incinerator; GHG emission

\section{Introduction}

Previously, $70 \%$ of sewage sludge in South Korea was disposed using the sea dumping method; however, sea dumping of sewage sludge has been completely prohibited since 2011 pursuant to the London Dumping Convention amended in 1996 [1]. Generally, the operating cost associated with the sludge handling was often reported to be a significant part of the overall operating cost in the wastewater treatment plant [2]. Also, sewage sludge management is a growing problem, especially in highly populated areas [3]. Consequently, incineration, with its advantages of large sewage sludge weight reduction effects, excellent stability, and transformation of sewage sludge into solid fuel, has come to the fore as an alternative for sewage sludge disposal. Due to these advantages, incineration has become the main method of sewage sludge disposal in many countries, including Germany and Japan [4-6]. 
According to the IPCC (Intergovernmental Panel on Climate Change) guidelines, $\mathrm{CO}_{2}$ emissions from biomass fractions should be excluded from the entire amount of $\mathrm{CO}_{2}$ emissions when calculating $\mathrm{CO}_{2}$ emissions and should be separately reported due to their "carbon neutrality". Sewage sludge is one of the representative biomass fuels. It is mixed with fossil fuels to achieve greenhouse gas reduction or is used by itself as a fuel to replace fossil fuels [7-9].

Municipal waste and industrial waste incineration facilities are excluded from biomass fractions when they calculate $\mathrm{CO}_{2}$ emissions. Sewage sludge incinerators do not estimate $\mathrm{CO}_{2}$ emissions when estimating GHG (Greenhouse Gases) emissions as $\mathrm{CO}_{2}$ emissions were considered as $100 \%$ biomass fractions. Therefore, GHG emissions from sewage sludge incineration facilities are calculated only for Non- $\mathrm{CO}_{2}$ emissions [10-12].

However, some studies reported that the biomass fraction of sewage sludge might not be $100 \%$ [13-15]. If, as reported in some studies, the biomass fraction of sewage sludge is not $100 \%$, $\mathrm{CO}_{2}$ emissions should be considered when greenhouse gas emissions are calculated. Therefore, it is necessary to accurately estimate and reflect the biomass fraction of sewage sludge in order to improve the reliability of greenhouse gas emissions from sewage sludge incineration facilities.

The present study aims to figure out how biomass fraction should be applied when greenhouse gas emissions in sewage sludge incineration facilities are calculated.

\section{Methods}

The present study seeks to figure out how biomass fraction should be applied in the calculation of greenhouse gas emissions in sewage sludge incineration facilities. To this end, we planned to analyze the biomass fraction of sewage sludge inputted into sewage sludge incineration facilities and the biomass fraction of gases collected from final incineration and to compare the resultant values to figure out the biomass fraction of sewage sludge incineration facilities.

\subsection{Selection of Objective Facilities}

The sewage sludge incineration facility located in Gyeonggi-do was selected for the reason that, on average, at least 150 tons of sewage sludge are generated from it per day. The selected sewage sludge incineration facility uses the fluidized bed incineration (which is predominantly used in sewage sludge incineration facilities in South Korea); the prevention facilities installed in the sewage sludge incineration facility are a Selective Non-Catalytic Reduction (SNCR) facility, a nitrogen oxide removing facility, a Bag Filter, a dust removing facility, a semi-dry reaction tower, and a wet wash tower. Sewage sludge samples and sewage sludge incineration exhaust gas samples were collected in January-March 2015. The current conditions of the subject facility are shown in Table 1.

Table 1. Characteristics of the sewage sludge incinerators included in the study.

\begin{tabular}{ccc}
\hline Classification & Facility Name & Capacity \\
\hline Incineration facility & Incinerator & $150 \mathrm{ton} /$ day \\
\hline & SNCR & $673 \mathrm{~N} \cdot \mathrm{m}^{3} / \mathrm{min}$ \\
Air pollution control devices & bag filter dust collector & $427 \mathrm{~N} \cdot \mathrm{m}^{3} / \mathrm{min}$ \\
& SDR & $427 \mathrm{~N} \cdot \mathrm{m}^{3} / \mathrm{min}$ \\
& Wet Scrubber & $427 \mathrm{~N} \cdot \mathrm{m}^{3} / \mathrm{min}$ \\
\hline
\end{tabular}

\subsection{Sampling of Waste Incinerator Facility}

In many EU countries, as well as in the USA, Japan, and Australia, continuous measurement methods are presented and recommended for greenhouse gas measurement in waste incineration facilities in order to enhance reliability [16-18].

The Mandatory Reporting Rule (MRR) in the USA for greenhouse gases presents the standards for incineration exhaust gas samples for the analysis of biomass fraction of incineration facilities. To meet 
the standards for samples of the MRR, incineration exhaust gases should be continuously collected for $24 \mathrm{~h}$ until the level of ASTM D 6866-08 can be satisfied. In the present study, pursuant to the U.S. mandatory greenhouse gas reporting rule, greenhouse gas samples were continuously collected for $24 \mathrm{~h}$. In South Korea, air pollutants are analyzed and monitored in real-time using automatic remote chimney monitoring systems. Incineration exhaust gases were collected at the rear end of a TMS (Tele-Monitoring System), which is a real-time air pollutant analysis device, using an incineration exhaust gas collecting device made by the present authors. The incineration exhaust gas collecting system is shown in Figure 1. The incineration exhaust gas collecting device consisted of a device to cool down high-temperature gases to $3{ }^{\circ} \mathrm{C}$ to facilitate incineration exhaust gas collection for $24 \mathrm{~h}$ (Alpha, Hwaseong-si, Korea), a drain pump for the discharge of cooled moisture (Alpha, Hwaseong-si, Korea), an electronic mass flow meter for the collection of incineration exhaust gases at a constant flow rate (Alicat Scientific, Tucson, AZ, USA), and a pump (KNJ, Seoul, Korea). Samples of sewage sludge for further analysis were sampled in the sewage sludge reservoir.

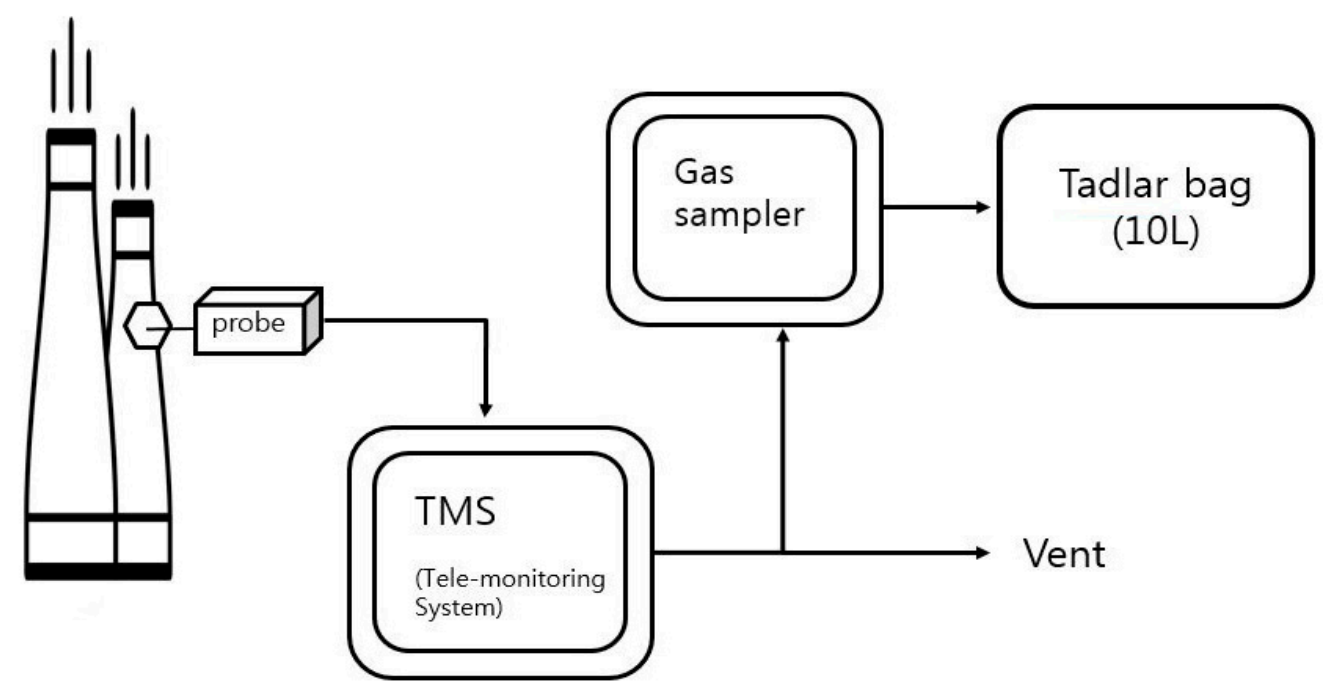

Figure 1. Schematic of the field setup for flue gas sampling of the incinerator.

\subsection{Analysis of the Biomass Fraction}

Official test methods related to biomass fraction analysis include ASTM D 6866, DS/CEN/TS 15440, and CEN/TR 15591. The official test methods include ${ }^{14} \mathrm{C}$ methods, Selective Dissolution Methods, and Balance Methods. In addition, many related studies use other relevant methodologies to analyze biomass fractions [19-24].

In the present study, the ${ }^{14} \mathrm{C}$ method was used to calculate the biomass fractions of sewage sludge and sewage sludge incineration exhaust gases. According to the official test methods, ${ }^{14} \mathrm{C}$ methods include LSC (Liquid Scintillation Counter), AMS (Accelerator Mass Spectrometer), and IRMS (Isotope Ratio Mass Spectrometer). In the present study, the application of ASTM-D6866 and AMS analysis method was used. The AMS method enables the analysis of tiny quantities ( $1 \mathrm{~g})$ and has a precision that is 105 times higher than the general mass analysis devices [25].

The AMS analysis is suitable for the carbon dating of small samples as it allows the number of atoms of different isotopes of carbon to be counted directly, instead of their ratio having to be inferred from the (very low) level of radioactivity of the sample.

The application of ASTM-D6866 to derive a "Biogenic carbon content (biomass fraction)" is built on the same concepts as radiocarbon dating, but without use of the age equations. It is done by deriving a ratio of the amount of radiocarbon $\left({ }^{14} \mathrm{C}\right)$ in an unknown sample to that of a modern reference standard. The modern reference standard used in radiocarbon dating is a NIST (National Institute of Standards and Technology) standard with a known radiocarbon content equivalent approximately to 
the year AD 1950. AD 1950 was chosen since it represented a time prior to thermo-nuclear weapons testing which introduced large amounts of excess radiocarbon into the atmosphere with each explosion (termed "bomb carbon"). This was a logical point in time to use as a reference for archaeologists and geologists. Therefore, 1950 is used as the reference year in accordance with "fractions of modern carbon (FM)" as below and biomass fractions are calculated by comparing the ratios of radioactive carbon isotopes ${ }^{14} \mathrm{C} /{ }^{12} \mathrm{C}$ existing in the standard sample and the analysis sample.

$$
f_{\mathrm{M}, \text { Sample }}=\frac{\left(\frac{{ }^{14} \mathrm{C}}{{ }^{12} \mathrm{C}}\right)_{\text {sample }}}{\left(\frac{{ }^{14} \mathrm{C}}{{ }^{12} \mathrm{C}}\right)_{\mathrm{AD} 1950}}
$$

$f_{\mathrm{M} \text {,Sample }}$ is the promptly measured parameter; however, the fraction of biogenic or fossil carbon (\%Bio C (biomass fraction), \%Fos C (fossil carbon fraction)) has more substantive relevance.

$$
\% \text { Bio C }=100 \%-\% \text { Fos C }=\left(\frac{f_{\mathrm{M}, \text { sample }}}{f_{\mathrm{M}, \mathrm{bio}}}\right) \times 100 \%
$$

Since ${ }^{14} \mathrm{C}$ in fossil matter is completely decayed, the content of biogenic carbon (\%Bio C) is directly proportional to the ${ }^{14} \mathrm{C}$ fraction in the emitted $\mathrm{CO}_{2}$.

\section{Result and Discussion}

\subsection{Biomass Fraction of Sewage Sludge}

To calculate the biomass fractions of sewage sludge and sewage sludge incineration exhaust gases, the sewage sludge and sewage sludge incineration exhaust gas samples were collected three times in total, once per month from January to March; furthermore, the biomass fractions were analyzed using the AMS method.

According to the results of the biomass fractions of sewage sludge sample analysis, the average biomass fraction was $76.92 \%$ and the range of biomass contents was $76.25 \%-77.38 \%$ depending on the time of the sample collection. The standard deviation of the biomass fractions of sewage sludge samples was 0.59 , suggesting that the biomass fractions were not very different across different time periods (see Table 2 below).

Table 2. The result of biomass fraction analyzed of sewage sludge.

\begin{tabular}{cc}
\hline Sampling & Biomass Fraction (\%) \\
\hline 1 & 77.38 \\
2 & 76.25 \\
3 & 77.12 \\
Mean & 76.92 \\
SD & 0.59 \\
\hline
\end{tabular}

\subsection{Biomass Fraction of Sewage Sludge Flue Gas}

The average biomass fraction of incineration exhaust gases from the sewage sludge incineration facility amounted to $76.56 \%$. The biomass fractions of the incineration exhaust gases were in the range of $74.45-78.20 \%$ across different times of samples and the standard deviation was 1.92 , indicating that the biomass fractions were not very different across different periods of time (see Table 3 below). 
Table 3. The result of biomass fraction analyzed of flue gas from sewage sludge.

\begin{tabular}{cc}
\hline Sampling & Biomass Fraction (\%) \\
\hline 1 & 74.45 \\
2 & 77.02 \\
3 & 78.20 \\
Mean & 76.56 \\
SD & 1.92 \\
\hline
\end{tabular}

\subsection{Comparison of Biomass Fraction in Objective Sewage Sludge Incinerator}

Sewage sludge and sewage sludge incineration exhaust gas samples were simultaneously collected from the sewage sludge incineration facility and the biomass fractions were compared. The differences in the biomass fractions were smaller than approximately $3 \%$, indicating that the biomass contents of sewage sludge and sewage sludge incineration exhaust gases were not very different. The biomass fractions of the samples collected for the first time showed a difference of approximately $3 \%$, while those of the samples collected for the second and third time showed differences below $1 \%$.

The biomass fractions of sewage sludge, that is the subject of incineration by the sewage sludge incineration facility and those of sewage sludge incineration exhaust gases that are finally emitted after incineration, were in the range of 74.45-78.2\%; none of the two results showed a biomass fraction of $100 \%$. Therefore, when calculating greenhouse gas emissions, sewage sludge incineration facilities should consider fossil carbon fractions excluding biomass fractions (see Figure 2 below).

According to Giger (1984) and McEvoy (1985) [14,15], in the analysis of sewage sludge, Linear Alkylbenzene Sulphonate (LAS) and 4-Nonylphenol components contained in surfactants, such as dishwashing detergents, liquids and shampoos, that were not completely treated during sewage treatment remained in the sewage sludge. This is the reason why we included fossil fuel-based carbon in sewage sludge in the present study.

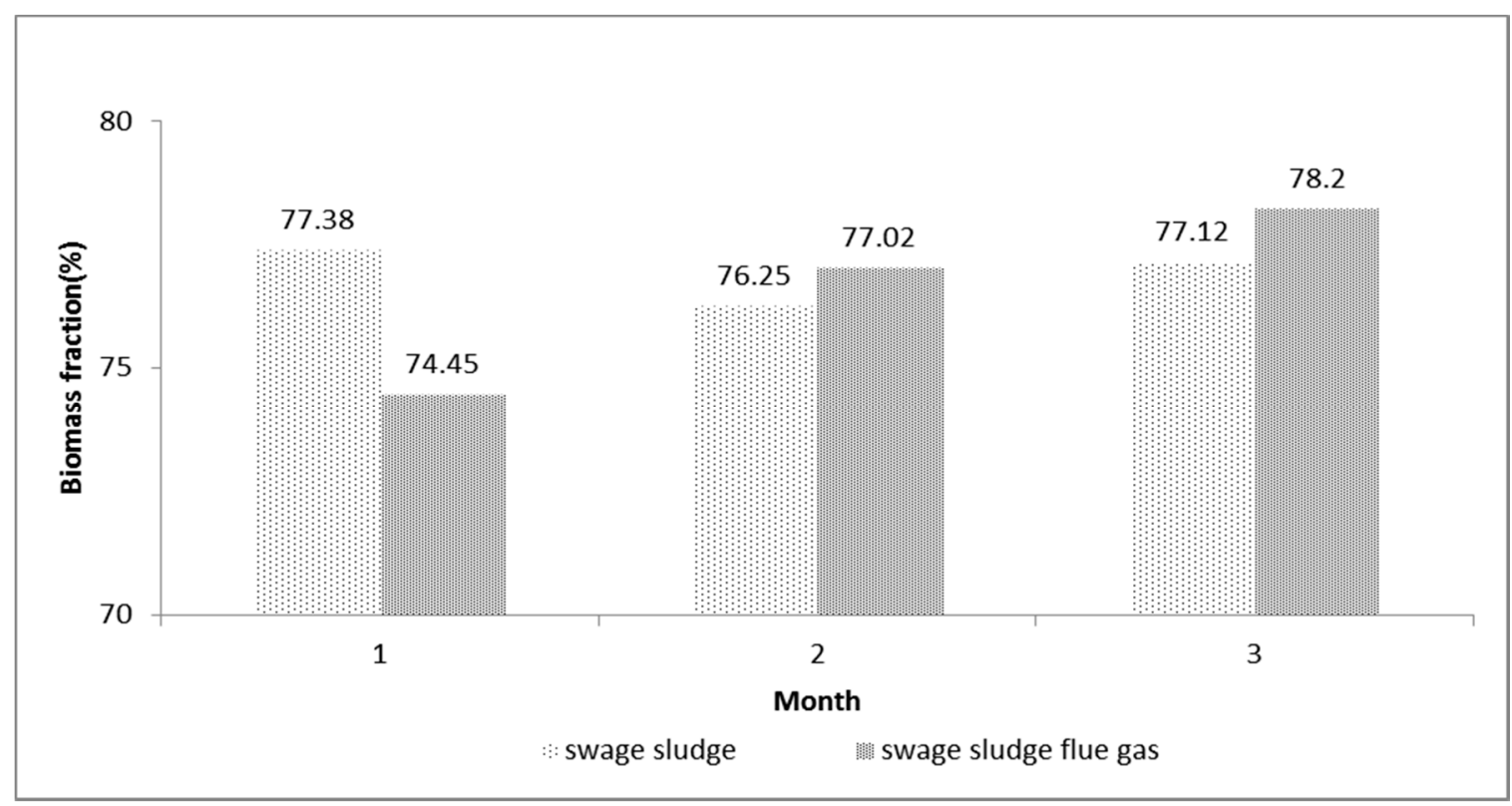

Figure 2. Comparison between sewage sludge and sewage sludge flue gas of the biomass fraction.

\section{Conclusions}

In the present study, attempts were made to examine how to apply biomass contents to the calculation of greenhouse gas emissions from sewage sludge incineration facilities. To this end, 
the biomass fractions of sewage sludge inputted into the subject incineration facility and those of sewage sludge incineration exhaust gases finally emitted were analyzed using the ${ }^{14} \mathrm{C}$ Method.

Sewage sludge and sewage sludge incineration exhaust gas samples were simultaneously collected three times between January and March 2015.

According to the results of the analysis of biomass fractions, the average biomass fraction of the sewage sludge samples was $76.92 \%$ and that of the incineration exhaust gases from the sewage sludge incineration facility was $76.56 \%$, suggesting no big difference on average. The biomass contents of both the sewage sludge and the sewage sludge incineration exhaust gases did not amount to $100 \%$. The reason behind this finding could be the fact that Linear Alkylbenzene Sulphonate (LAS) and 4-Nonylphenol components that are contained in surfactants, such as dishwashing detergents, liquids, and shampoos, were not completely treated during sewage treatment and remained in the sewage sludge (see Giger (1984) and McEvoy (1985) [14,15]).

At present, in many countries such as South Korea, Japan, and Germany, when calculating greenhouse gas emissions from sewage sludge incineration facilities, all $\mathrm{CO}_{2}$ emissions from sewage sludge are judged to be biomass and only the greenhouse gas emissions that correspond to non- $\mathrm{CO}_{2}$ gases are calculated as greenhouse gas emissions. However, since, according our results, the fraction of sewage sludge is not $100 \%$ biomass, if $\mathrm{CO}_{2}$ emissions are excluded according to the existing greenhouse gas emission calculation method, the amount of emissions may be underestimated.

Therefore, to accurately calculate greenhouse gas emissions from sewage sludge incineration facilities, $\mathrm{CO}_{2}$ emissions should be calculated in consideration of the fossil carbon fractions of sewage sludge. Further studies aiming to figure out the biomass fractions of $\mathrm{CO}_{2}$ emitted from sewage sludge incineration facilities and to compare greenhouse gas emissions according to $\mathrm{CO}_{2}$ emission calculation methods using such biomass fractions will improve the reliability of greenhouse gas inventories of sewage sludge incineration facilities.

Acknowledgments: This work is financially supported by Korea Ministry of Environment (MOE) as "Graduate School specialized in Climate Change". This subject is supported by the Korea Ministry of Environment as "Climate Change Correspondence R\&D Program (2016001300004)".

Author Contributions: All the authors contributed towards the completion of the paper. Eui-chan Jeon guided the experiments and designed the study. Seongmin Kang wrote the paper and analyzed the data, data interpretation. Seungjin Kim, Jeongwoo Lee, Youngjae Jeon conducted the experiments, analyzed the results, and Ki-Hyun Kim review and modified the paper.

Conflicts of Interest: The authors declare no conflict of interest.

\section{References}

1. Kim, M.Y.; Kim, J.K.; Lee, H.D.; Kim, S.C. Combustion Characteristics of Sewage sludge-bituminous coal mixture. Appl. Chem. 2009, 13, 93-96.

2. Teh, C.Y.; Budiman, P.M.; Shak, K.P.Y.; Wu, T.Y. Recent advancement of coagulation-flocculation and its application in wastewater treatment. Ind. Eng. Chem. Res. 2016, 55, 4363-4389. [CrossRef]

3. Vochozka, M.; Maroušková, A.; Váchal, J.; Straková, J. Appraisal of changes in sewage sludge management. Int. J. Environ. Sci. Technol. 2016, 13, 1607-1614. [CrossRef]

4. Fytili, D.; Zabaniotoua, A. Utilization of sewage sludge in EU application of old and new methods-A review. Renew. Sustain. Energy Rev. 2008, 12, 116-140. [CrossRef]

5. Werther, J.; Ogada, T. Sewage sludge combustion. Prog. Energy Combust. Sci. 1999, 25, 55-116. [CrossRef]

6. Takahiro, M.; Yoshizo, S.; Hidekazu, N.; Takafumi, Y.; Takami, K.; Hitoshi, H.; Seiichiro, O. Combustion characteristics of sewage sludge in an incineration plant for energy recovery. Fuel Process. Technol. 2009, 90, 778-783.

7. Zabaniotoua, A.; Theofiloub, C. Green energy at cement kiln in Cyprus-Use of sewage sludge as a conventional fuel substitute. Renew. Sustain. Energy Rev. 2008, 12, 531-541. [CrossRef]

8. David, M.K. Biodiesel Production from Municipal Sewage Sludges. Energy Fuels 2010, 24, 2791-2794.

9. Shireen, M.K.; Debabrata, D. Biohydrogen as a renewable energy resource-Prospects and potentials. Int. J. Hydrog. Energy 2008, 33, 258-263. 
10. Environment Agency Austria Umweltbundesamt. Austria's National Inventory Report 2015; Environment Agency Austria Umweltbundesamt: Canberra, Australia, 2015.

11. Federal Environment Agency (UBA). National Inventory Report for the German Greenhouse Gas Inventory 1990-2013; Federal Environment Agency (UBA): Dessau, Germany, 2015.

12. Greenhouse Gas Inventory Office of Japan (GIO). National Greenhouse Gas Inventory Report of Japan; Greenhouse Gas Inventory Office of Japan (GIO): Tsukuba-shi, Japan, 2015.

13. Beta Analytic, USA Sewage Sludge. Available online: http://www.betalabservices.com/renewable-carbon/ sewage-sludge.html (accessed on 2 April 2016).

14. McEvoy, J.; Giger, W. Accumulation of linear alkylbenzenesulphonate surfactants in sewage sludges. Naturwissenschaften 1985, 72, 429-431. [CrossRef]

15. Giger, W.; Brunner, P.H.; Schaffner, C. 4-Nonylphenol in sewage sludge: Accumulation of toxic metabolites from non-ionic surfactants. Science 1984, 225, 623-625. [CrossRef] [PubMed]

16. Department of the Environment (DOE). Technical Guidelines for the Estimation of Greenhouse Gas Emissions by Facilities in Australia; Department of the Environment (DOE): Canberra, Australia, 2012.

17. Environmental Protection Agency (EPA). 2011. 40 CFR Part 98 Mandatory Reporting of Greenhouse Gases, Federal Register; Environmental Protection Agency (EPA): Washington, DC, USA, 2011.

18. European Commission. Biomass Issues in the EU ETS; MRR Guidance Document; European Commission: Brussels, Belgium, 2012.

19. ASTM International. 6866: Standard Test Methods for Determining the Bio based Content of Solid, Liquid, and Gaseous Samples Using Radiocarbon Analysis; ASTM International: West Conshohocken, PA, USA, 2007.

20. Anna, W.L.; Karsten, F.; Niels, H.P.; Johann, F.; Helmut, R.; Thomas, A. Biogenic carbon in combustible waste: Waste composition, variability and measurement uncertainty. Waste Manag. Res. 2013, 31, 56-66.

21. Mohn, J.; Szidat, S.; Fellner, J.; Rechberger, H.; Quartier, R.; Buchmann, B.; Emmenegger, L. Determination of biogenic and fossil $\mathrm{CO}_{2}$ emitted by waste incineration based on ${ }^{14} \mathrm{CO}_{2}$ and massbalances. Bioresour. Technol. 2008, 99, 6471-6479. [CrossRef] [PubMed]

22. Mohn, J.; Szidat, S.; Zeyer, K.; Emmenegger, L. Fossil and biogenic $\mathrm{CO}_{2}$ from waste incineration based on a yearlong radio carbon study. Waste Manag. 2012, 32, 1516-1520. [CrossRef] [PubMed]

23. Levin, I.; Kromer, B.; Schmidt, M.; Sartorius, H. A novel approach for independent budgeting of fossil fuel $\mathrm{CO}_{2}$ over Europe by ${ }^{14} \mathrm{CO}_{2}$ observations. Geophys. Res. Lett. 2003, 30, 2194. [CrossRef]

24. Palstra, S.W.L.; Meijer, H.A.J. Carbon-14 based determination of the biogenic fraction of industrial $\mathrm{CO}_{2}$ emissions. Appl. Valid. Bioresour. Technol. 2010, 101, 3702-3710. [CrossRef] [PubMed]

25. Matthias, R. Radiocarbon Measurement of Micro-Scale Samples-A Carbon Dioxide Inlet System for AMS; Philosophisch-Naturwissenschaftlichen Fakulttp der Universiter Bern: Bern, Switzerland, 2008. 